\title{
Prediction of body fat through body adiposity index and bioelectrical impedance analysis in a sample of physically active Mexican students \\ Predicción de grasa corporal mediante el índice de adiposidad corporal y análisis de impedancia bioeléctrica en una muestra de estudiantes Mexicanos físicamente activos
}

*Paulina Yesica Ochoa-Martinez, *Javier Arturo Hall-López, *Ileana Solano-Pineda, **Luis Roberto Monreal Ortiz, ***Yamileth Chacón-Araya, ***José Moncada-Jiménez

*Autonomous University of Baja California (México), **Autonomous University of Sinaloa (México), ***University of Costa Rica (Costa Rica)

\begin{abstract}
Objective: To compare the body fat percentage \%BF predicted through the body adiposity index (BAI) BAI in a sample of physically active Mexican college students, using bioelectrical impedance analysis (BIA) as reference method. Methods: 78 volunteered university students (20.67 \pm 1.69 yrs.) partake in study considered as highly active; the \%BF determined by BIA was performed using Inbody 720; BAI was calculated by anthropometric assessment from hip and height measures calculated as follows: BAI=[hip circumference (cm)/height (m)1.5]-18. Pearson's correlation coefficient was used to evaluate the association between BAI and \%BF assessed by BIA. Results: The correlations of \% BF between BIA and the estimated by BAI were $r=0.81, p<0.001$ in man and $r=0.69, p<0.001$ in women. Paired t-test in man showed a significant mean difference in $\% \mathrm{BF}$ between methods $(\mathrm{p}=0.001)$. The bias of the body adiposity was $5.77 \pm 4.2 \%$ (CI95\% $=4.40$ to 7.14$)$, indicating that the body adiposity index method measured lower \%BF than the bioelectrical impedance. Paired t-test in women did not show significant difference $(p=0.355)$. Lin's

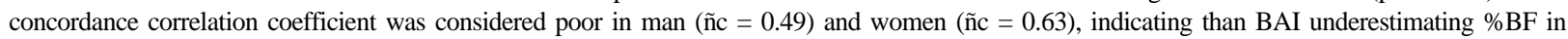
relation to the BIA. Conclusion: In physically active Mexican college students, BAI presented low agreement with \%BF measured by BIA; therefore, BAI is not recommended for \%BF prediction in this sample studied.
\end{abstract}

Keywords: Body fat percent, Bioelectrical impedance, Young adults, Physical activity.

Resumen. Objetivo: Comparar el porcentaje de grasa corporal \% BF predicho por el índice de adiposidad corporal (BAI) y el análisis de impedancia bioeléctrica (BIA) en una muestra de estudiantes universitarios Mexicanos físicamente activos. Método: 78 estudiantes universitarios (Edad media= 20,67 $\pm 1,69$ años) voluntarios considerados físicamente activos mediante el cuestionario (IPAQ) participaron en el estudio; Para determinar el \%GC con el método de referencia el AIB se realizó con el equipo Inbody 720; el IAC se determinó mediante valoración antropométrica de las medidas circunferencia de cadera y talla calculándose con la fórmula: IAC (\%GC)=[circunferencia de cadera (cm)/talla(m)1,5]-18. Resultados: Las correlaciones de Pearson del \%GC entre IAC y las estimada por AIB fue de $\mathrm{r}=0,81, \mathrm{p}<0,001$ en hombres y $\mathrm{r}=0.69$, $\mathrm{p}<0.001$ en mujeres. La prueba t-Student en

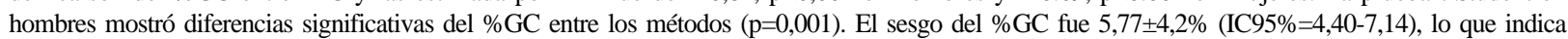
que la media del \%GC por IAC fue inferior al AIB. La prueba t-Student en mujeres no mostró diferencias significativas ( $\mathrm{p}=0,355)$. La concordancia del coeficiente de correlación de Lin se consideró pobre en hombres (ñc=0,49) y mujeres (ñc=0,63), indicando que el IAC subestima él \%GC en relación con el AIB. Conclusión: En los estudiantes universitarios mexicanos físicamente activos evaluados, el IAC presentó baja concordancia del \%GC medido por AIB; por lo anterior, el IAC no se recomienda para predecir el \%GC en esta muestra estudiada.

Palabras clave: porcentaje de grasa corporal, análisis de impedancia bioeléctrica, adultos jóvenes, actividad física.

\section{Introduction}

According with the National Health and Nutrition 2012 in Mexico the prevalence of obesity (body mass index e» 30 ) was $24 \%$ in women and 20.4\% in man between the ages of 20-29years old and the prevalence of abdominal obesity (waist circumference e»88 $\mathrm{cm}$ ) showed $63.6 \%$ in women and 43.9\% in man(ENSANUT, 2012), there is scientific evidence pointing than time in college coincides with the beginning of the increase of overweight and obesity trends and decrease the physical activity level (Sacheck, Kuder, \& Economos, 2010); Presence of obesity in young adults have been related to sedentary lifestyle and metabolic risk factors for cardiovascular disease and type 2 diabetes (Meckel et al., 2011, Ureña Bonilla, Blanco Romero, \& Salas Cabrera, 2015, Práxedes et al., 2016); evidence from a systematic review and meta-analysis clearly show that active population had more absence of these factors (Hebden, Chey, \& Allman-Farinelli, 2012).

The obesity trends in young adults should be monitored to avoid pathologies in the future as cardiovascular diseases and type 2 diabetes (Sacheck et al., 2010); anthropometry indicators such body mass index (BMI=body weight in $\mathrm{kg} /$ body height in $\mathrm{m}^{2}$ ) and waist circumference (cm) have as been used to define overweight and obesity, these methods are preferred in epidemiological studies for inexpensive, noninvasive assessment and easy to apply in large samples (Hebden et al., 2012, Lutoslawska et al., 2014). However, this measurement has been reported to lack accuracy to assess body fatness and is different for males and females with similar proportions of body adiposity (Okorodudu et al., 2010, Gupta \& Kapoor, 2014), By other hand, body mass index and waist circumference do not reflect the percentage of body fat (\%BF) in

Fecha recepción: 25-01-17. Fecha de aceptación: 07-11-17 Javier Arturo Hall-López javierhall@uabc.edu.mx young adults and collegiate athletes (Brooks et al., 2007, Ode et al., 2007, Esco et al., 2011).

To diminish this feature, a new adiposity index called the «body adiposity index» (BAI) has been proposed, was developed with data from Mexican American adults of both sexes, from 18 to 67 years old and tested in African American Sample (Bergman et al., 2011), and is currently under evaluation in different populations BAI is calculated from hip and height measures as follows: BAI (\% body fat) = [hip circumference $(\mathrm{cm}) /$ height $(\mathrm{m}) 1.5]-18$.

However, validation studies performed in other populations are controversial. For instance, BAI has been not proven valid for populations as Chinese adults (Zhang et al., 2014), Caucasian European population in Norway (Vinknes et al., 2014), Brazilian women (Cerqueira et al., 2013) United States older populations (Chang et al., 2013) and Costa Rican young adults (Carpio-Rivera et al., 2015). However, the method has proven valid for other populations, including older Japanese (Kanehisa \& Fukunaga, 2013) and Iranian adolescents (Ejtahed et al., 2014).

BAI was validated by using dual-energy X-ray absorptiometry (DEXA) (Bergman et al., 2011). However, the use of this method is limited due to the fear radiation emitted, it is expensive, time consuming and require equipment than is often limited to research units, this research considered the BIA as widely method used in the clinical practice and sport science to assess the body fat (Macias et al., 2014). BIA method has showed accuracy in predicting body fatness in general population, using DEXA as the «gold standard», BIA evaluates the resistance of an electric current exerted across the fat free mass due to its high water and electrolytes (sodium and potassium) content; these technique is based on the notion than tissues rich in water and electrolytes are less resistant to the passage of electricity than adipose tissue.

In Mexico there is a lack references in body fat composition in young groups, the body adiposity Index has not been validated in 
Mexican young adults. Therefore, to diminish this feature the study was designed to verify the prediction of \%BF estimated through the BAI and BIAina Sample of Physically Active Mexican College Students.

\section{Methods}

\section{Participants and setting}

Participants were recruited on basis of advertisements in the Faculty of Sport of the Autonomous University of Baja California. Each participant was given an appointment for ask for general information, applying a questionnaire to determine the physical activity level, participants were instructed to wear a short, a t-shirt, and remove any metal and jewelry from their persons also before the of body composition testing session the participants were asked not doing any physical exercise $24 \mathrm{~h}$ before the test, maintaining good hydration and do not drink $4 \mathrm{~h}$ prior the test, perform the last defecation and/or urination 30 min before the start of test scheduled, do not eating food $4 \mathrm{~h}$ before the test, in case of women it was not considered the date appointment with the estrogenic phase of their menstrual cycle; the testing session was developed in the Laboratory of Human Motricity Biosciences of the Faculty of Sports, Autonomous University of Baja California.

In order to estimate the physical activity level the short format (Spanish version) of the international physical activity questionnaire IPAQ (Craig et al., 2011) was used. The short IPAQ allows categorical and continuous measurements of physical activity realized in the past 7 days, the continuous score allows the estimation of the weekly energy expenditure expressed in MET minutes/week (Metabolic Equivalent Task-Minutes). This is obtained by multiplying the value of energy expenditure for the given physical activity in MET by the weekly frequency (days per week) and the time in minutes (minutes per day), according to this questionnaire, all types of walking are given an average MET value of 3.3, all moderate intensity physical activity is valued at 4 and vigorous intensity physical activity is valued at 8 . The categorical score classifies individual into three categories; 'Inactive', 'Moderately active' and 'Highly active, as inclusion criteria only subjects how achieve highly active category were included in the study.

This research was cross-sectional analytical study where participants were measured only one time. In total seventy eight college students volunteered to partake in study with a mean age of $20.67 \pm 1.69 \mathrm{yrs}$. The present study followed the ethical principles regarding human experimentation proposed by the Helsinki declaration (Puri et al., 2009); all the subjects provided a written consent in order to participate in the study that was approved by the research program of the Faculty of Sports of the Autonomous University of Baja California (Protocol N 004/2014).

\section{Measures and procedures}

Anthropometric measurement

Anthropometric assessment was carried out by a certified level two anthropometrist of the Society for the Advancement of Kinanthropometry (ISAK) (Marfell-Jones et al., 2006) with a technical error of measurement less or equal to $1 \%$., Hip circumference $(\mathrm{cm})$ was measured to the nearest $0.1 \mathrm{~cm}$ at the level of the maximum extension of the buttocks in a horizontal plane using a Lufkin non-stretchable metal anthropometric tape (precision $0.1 \mathrm{~cm})$. Height $(\mathrm{cm})$ was performed using a wall-mounted stadiometer(Seca, model 220, Hamburg, Germany) (precision $0.1 \mathrm{~cm}$ ).

BAI was calculated from hip circumference and height using the formula: BAI (\% body fat $)=$ [hip circumference $(\mathrm{cm}) /$ height $(\mathrm{m}) 1.5]$ 18

\section{Bioelectrical impedance}

Bioelectrical impedance was obtained using Inbody 720 (Biospace Inc, Korea $\left.{ }^{\circledR}\right)$. The InBody 720 uses the segmental BIA method in order to examine the body as five cylinders (four limbs and a trunk), and measures impedance in these parts separately. Each subject was undressed except for underwear and placed in standing position and flexion of the scapulohumeral joint $30^{\circ}$; 8 electrodes were placed in the
Feet (metatarsal-calcaneal) and hands (2nd-5th metacarpal and phalanx of the thumb finger), all jewelry and wristwatches were removed before the analyzer started recording. The frequency of induction was evaluated with 5 different intensities (5, 50, 250, 500 and $1000 \mathrm{kHz}$ ), in order to directly measure the amount of extracellular and intracellular water, with a sensitivity of mass estimation fat $0.1 \mathrm{~kg}(0.1 \%)$.

\section{Analysis}

Statistical analyses were performed using statistical software (MedCalc version 11.5.1, Mariakerke, Belgium) and SPSS for Windows version 20 (IBM Corporation, New York, USA). Mean (M) and ( \pm SD) standard deviation were obtained to calculate the dependent variables. Statistical significance was set at $\mathrm{p}<0.05$. The BIA was used as the «reference method» to determine \%BF. Pearson's correlation coefficient was used to evaluate the association between body fat assessed by BAI and $\% \mathrm{BF}$ assessed bioelectrical impedance.

A paired sample t-test for each sex was used to test differences in mean \%BF obtained with BAI and BIA methods. Lin's concordance correlation coefficient was used to assess the reproducibility between body fat assessed bioelectrical impedance (Lin, 1989); Lin's strength of agreement was considered as poor $(<0.90)$, moderate $(0.90-0.95)$, substantial (0.95- 0.99), and almostperfect (>0 0.99) (Lin, 1989, McBride, 2005); The plot of the differences between BIA and BAI was studied by the Bland-Altman procedure (Bland \& Altman, 1986).

\section{Results}

Descriptive statistics for the sample are shown in table 1.

The correlation of $\%$ BF between bioelectrical impedance and the estimated by body adiposity were $\mathrm{r}=0.81, \mathrm{p}<0.001$ in man and $\mathrm{r}=$ $0.69, \mathrm{p}<0.001$ in women. Paired t-test in man showed a significant mean difference in $\% B F$ between methods $(\mathrm{p}=0.001)$. The bias of the BAI was $5.77 \pm 4.2 \%($ CI95\% $=4.40$ to 7.14$)$, indicating that the BAI method measured lower \%BF than the BIA. Paired t-test in women did

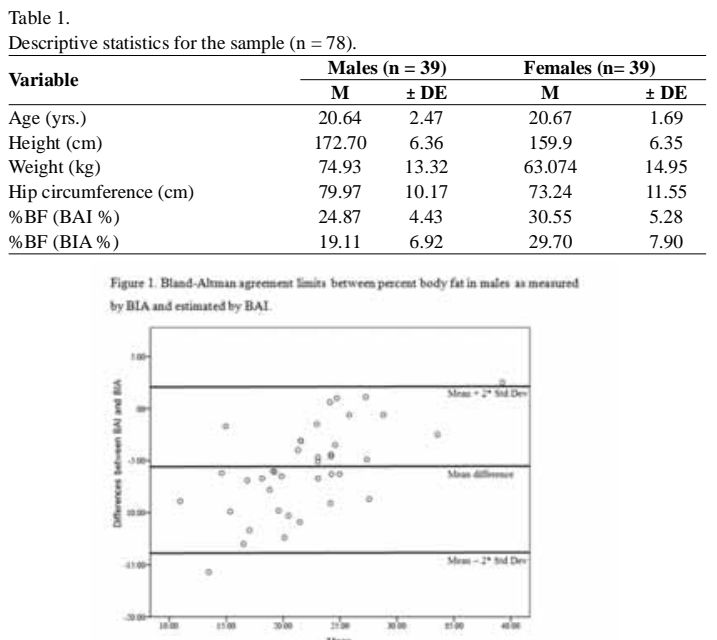

Figure 1. Agreement limits of Bland-Altman between the percent of body fat in man measured by BIA and estimated by BAI. The Bland-Altman plot depicts BAI underestimating $\% \mathrm{BF}$ in relation to the "reference method" BIA.

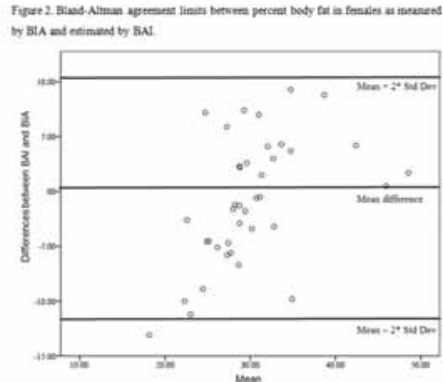

Figure 2. Agreement limits of Bland-Altman between the percent of body fat in women measured by BIA and estimated by BAI. The Bland-Altman plot depicts BAI underestimating $\% \mathrm{BF}$ in relation to the "reference method" BIA 
not show significant difference $(\mathrm{p}=0.355)$.

Lin's concordance correlation coefficient was considered poor in man (ñc $=0.49$ ). The Bland-Altman plot (Figure 1) showed BAI underestimating \%BF in relation to the BIA.

Lin's concordance correlation coefficient was considered poor women (ñc $=0.63$ ). The Bland-Altman plot (Figure 2) showed BAI underestimating \% $\mathrm{BF}$ in relation to the BIA.

\section{Discussion}

The aim of this study was to compare the body fat percentage \%BF predicted through the body adiposity index (BAI) BAI in a sample of physically active Mexican college students, using bioelectrical impedance analysis (BIA) as reference method, the correlations of \% BF between BIA and the estimated by BAI were $r=0.81, p<0.001$ in man and $r=0.69, p<0.001$ in women. BAI presented low agreement with $\% \mathrm{BF}$ measured by BIA; therefore, $\mathrm{BAI}$ is not recommended for $\% \mathrm{BF}$ prediction in this sample studied.

From the point of view of body composition assessment, ethnicity is a factor that influences the body fay, anthropometric profile and shape of an individual (Carroll et al., 2008, Hebden et al., 2012) regarding this BAI was validated with data from Mexican American adults (Bergman et al., 2011, Carroll et al. 2008), refers than male and female Hispanic individuals with similar ages have been observed to have a lower height and weight than other ethnicity groups, in spite of the sample in our study were young Mexican the data showed than BAI index was ineffective in predicting \%BF. On this topic Lutoslawska et al. 2014, have reported poor correlation coefficient in Lin's concordance between \%BF and BAI in physical education students from Poland, However, a study performed in a sample of Central American physical education students BAI presented low agreement with BF\% measured by DXA (Carpio-Rivera et al. 2015). Regarding the assessment of obesity amongst physical education teachers previous studies has been reported $82.3 \%$ of combined overweight and obesity using BMI and abdominal obesity was $43.5 \%$ in males and $29.4 \%$ in females, those resulted were even higher than the Mexican national average (Hall et al. 2009, Hall et al. 2012), by other hand results of studies do not reflect accuracy of \%BF assessed with anthropometric measurements in active and sedentary university students (Brooks et al., 2007, Ode et al., 2007, Esco et al., 2011).

Although BAI has been reported to be effective in predicting \%BF in some populations and appeared to be of potential interest as a measure of \%BF in obesity populations (Gupta \& Kapoor, 2014, Kanehisa \& Fukunaga, 2013, Ejtahed et al., 2014); in clinical practices, specially nutrition and physical exercise area, clinicians should pay attention when perform the BAI and interpret the \%BF, due the accuracy in physically active people (Ode et al., 2007, Esco et al., 2011).

The present study is limited by the sample size, restricted to Mexican young physically active people, also because of the crosssectional design we cannot infer causality, despite of these limitations our data seem to be of importance in may contribute to better understand intervention strategies for weight loss and prevention of weight regain in young due inappropriate dietary habits, distorted body image and lack physical activity in college students (Donnelly et al., 2009); by other hand to our knowledge, there is a lack references than report the validation of the BAI in predicting \%BF in Mexican population.

\section{Conclusions}

In summary, based on these results the BAI showed poor concordance, low accuracy, precision and is not recommended method when estimating \%BF in a sample of physically active Mexican College Students. In the future will be appropriated more representative studies to clarify the cutoffs, accuracy and association of Body Adiposity Index according with age, sex, metabolic risk factors, health behaviors and other indicator of morbidity.

\section{References}

Bergman, R. N., Stefanovski, D., Buchanan, T. A., Sumner, A. E., Reynolds, J. C., Sebring, N. G, . . . Watanabe, R. M. (2011). A better index of body adiposity. Obesity (Silver Spring), 19(5), 10831089. doi: 10.1038/oby.2011.38

Bland, J. M., \& Altman, D. G. (1986). Statistical methods for assessing agreement between two methods of clinical measurement. Lancet, 8476, 307-310.

Brooks, Y., Black, D. R., Coster, D. C., Blue, C. L., Abood, D. A., Gretebeck, R. J. (2007). Body mass index and percentage body fat as health indicators for young adults. Am J Health Behav, 31(6):687700 .

Carpio-Rivera, E., Hernández-Elizondo, J., Salicetti-Fonseca, A., SoleraHerrera,A., Moncada-Jiménez, J. (2016). Predictive validity of the body adiposity index in Costa Rican students. Am J Hum Biol, 28(3):394-7. doi: 10.1002/ajhb.22800. 26.

Carroll, J. F., Chiapa, A. L., Rodriquez, M., Phelps, D. R., Cardarelli, K. M., Vishwanatha, J. K., ... Cardarelli, R. (2008). Visceral fat, waist circumference, and BMI: impact of race/ethnicity. Obesity (Silver Spring), 16(3), 600-607. doi: 10.1038/oby.2007.92

Cerqueira, M., Amorim, P., Magalhaes, F., Castro, E., Franco, F., Franceschini, S., ... Doimo, L. (2013). Validity of body adiposity index in predicting body fat in a sample of Brazilian women. Obesity (Silver Spring), 21(12), E696-699. doi: 10.1002/oby.20543

Chang, H., Simonsick, E. M., Ferrucci, L., \& Cooper, J.A. (2013). Validation Study of the Body Adiposity Index as a Predictor of Percent Body Fat in Older Individuals: Findings From the BLSA. J Gerontol A Biol Sci Med Sci, 69(9):1069-75. doi: 10.1093/gerona/ glt165. Epub 2013 Oct 24.

Craig, C. L., Marshall, A. L., Sjostrom, M., Bauman, A. E., Booth, M. L., Ainsworth, B. E., . . . Oja, P. (2003). International physical activity questionnaire: 12 -country reliability and validity. Med Sci Sports Exerc, 35(8), 1381-1395. doi: 10.1249/ 01.MSS.0000078924.61453.FB

Donnelly, J. E., Blair, S. N., Jakicic, J. M., Manore, M. M., Rankin, J. W., Smith, B. K., \& American College of Sports, M. (2009).American College of Sports Medicine Position Stand. Appropriate physical activity intervention strategies for weight loss and prevention of weight regain for adults. Med Sci Sports Exerc, 41(2), 459-471. doi: 10.1249/MSS.0b013e3181949333

Ejtahed, H. S., Asghari, G, Mirmiran, P., Hosseinpour-Niazi, S., SherafatKazemZadeh, R., Azizi, F. (2014). Body mass index as a measure of percentage body fat prediction and excess adiposity diagnosis among Iranian adolescents. Arch Iran Med, 17(6):400-5. doi: 014176/AIM.005.

Esco, M. R. (2013). The accuracy of the body adiposity index for predicting body fat percentage in collegiate female athletes. JStrength Cond Res, 27(6), 1679-1683. doi:10.1519/JSC.0b013e3182712714

Gupta, S., \& Kapoor, S. (2014). Body adiposity index: its relevance and validity in assessing body fatness of adults. ISRN Obes, 2014, 243294. doi: 10.1155/2014/243294

Hall López, J. A., Ochoa Martínez, P. Y., Sáenz-López Buñuel, P., Monreal Ortiz, L.R. (2009). [Comparative study of the physical activity level, nutrition state and abdominal obesity in physical education professors from the University Autonomous of Sinaloa and Huelva University]. Retos, 15:5-8.

Hall López, J. A., Ochoa Martínez, P. Y., Alarcón Meza, E. I. (2012). [Physical activity, nutritional state and abdominal obesity in physical culture profesors field]. Rev int med cienc act fís deporte,12:209220.

Hebden, L., Chey, T., \& Allman-Farinelli, M. (2012). Lifestyle intervention for preventing weight gain in young adults: a systematic review and meta-analysis of RCTs. Obes Rev, 13(8), 692-710. doi: 10.1111/j.1467-789X.2012.00990.x

Kanehisa, H., \& Fukunaga, T. (2013). Association between body mass 
index and muscularity in healthy older Japanese women and men. J Physiol Anthropol, 32(1):1-4. doi: 10.1186/1880-6805-32-4.

Lin, L. I. (1989). A concordance correlation coefficient to evaluate reproducibility. Biometrics, 45(1), 255-268.

Lutoslawska, G., Malara, M., Tomaszewski, P., Mazurek, K., Czajkowska, A., Kêska, A., ...Tkaczyk, J. (2014). Relationship between the percentage of body fat and surrogate indices of fatness in male and female Polish active and sedentary students. JPhysiol Anthropol,13;33:10. doi: 10.1186/1880-6805-33-10.

Macias, N., Quezada, A. D., Flores, M., Valencia, M. E., DenovaGutierrez, E., Quiterio-Trenado, M., . . . Salmeron, J. (2014). Accuracy of body fat percent and adiposity indicators cut off values to detect metabolic risk factors in a sample of Mexican adults. BMC Public Health, 14, 341. doi: 10.1186/1471-2458-14341

Marfell-Jones, M., Olds, T., Stewart, A., \& Carter, L. (2006). International standards for anthropometric assessment. Potchefstroom, South Africa: ISAK.

Meckel, Y., Galily, Y., Nemet, D., Eliakim, A. (2011)Changes in weight indexes and aerobic fitness of physical education students over three years of college. J. Hum. Sport Exerc, 6(1)112-21.

McBride, G. B. (2005). Using statistical methods for water quality management: issues, problems and solutions (Vol. 19.) Hoobek, NJ: John Wiley \& Sons.

National Institute of Public Health. Mexican National Health and Nutrition ENSANUT 2012: National results in adults. Morelos, México: National Institute of Public Health, 2012. Recent Findings, 2013. Available at: http://ensanut.insp.mx/; accessed on 01.12.2015.

Ode, J. J., Pivarnik, J. M., Reeves, M. J., Knous, J.L. (2007). Body mass index as a predictor of percent fat in college athletes and nonathletes. Med Sci Sports Exerc, 39(3):403-9.
Okorodudu DO, Jumean MF, Montori VM, Romero-Corral A, Somers VK, Erwin PJ, et al. (2010). Diagnostic performance of body mass index to identify obesity as defined by body adiposity: a systematic review and meta-analysis. Int J Obes (Lond), 34(5):791-9. doi: 10.1038/ijo.2010.5.

Práxedes A., Sevil, J., ; Moreno, A., del Villar, F., García-González, L. (2016). Niveles de actividad física en estudiantes universitarios: diferencias en función del género, la edad y los estados de cambio. Revista Iberoamericana de Psicología del Ejercicio y el Deporte, 11(1).

Puri, K. S., Suresh, K. R., Gogtay, N. J., \& Thatte, U. M. (2009). Declaration of Helsinki, 2008: implications for stakeholders in research. J Postgrad Med, 55(2), 131-134. doi:10.4103/00223859.52846

Sacheck, J. M., Kuder, J. F., \& Economos, C. D. (2010). Physical fitness, adiposity, and metabolic risk factors in young college students. Med Sci Sports Exerc, 42(6), 1039-1044. doi: 10.1249/ MSS.0b013e3181c9216b

The InBody720 for research grade analysis, The InBody720 for research grade analysis, 2014, Biospace Co. Ltd.: Seoul, Korea.

Ureña Bonilla, P., Blanco Romero., L, \& Salas Cabrera, J. Quality of life, anthropometric indicators and body satisfaction in a group of high school students. Retos, 27:62-66, 2015.

Vinknes, K. J., Elshorbagy, A. K., Drevon, C. A., Gjesdal, C. G., Tell, G. S., Nygard, O., . . . Refsum, H. (2013). Evaluation of the body adiposity index in a Caucasian population: the Hordaland health study. Am J Epidemiol, 177(6), 586-592. doi: 10.1093/aje/kws271

Zhang, Z. Q., Liu, Y.H., Xu, Y., Dai, X. W., Ling, W.H., Su, Y.X.,...Chen, Y. M. (2014). The validity of the body adiposity index in predicting percentage body fat and cardiovascular risk factors among Chinese. Clin Endocrinol(Oxf),81(3):356-62. doi: 10.1111/cen.12351.

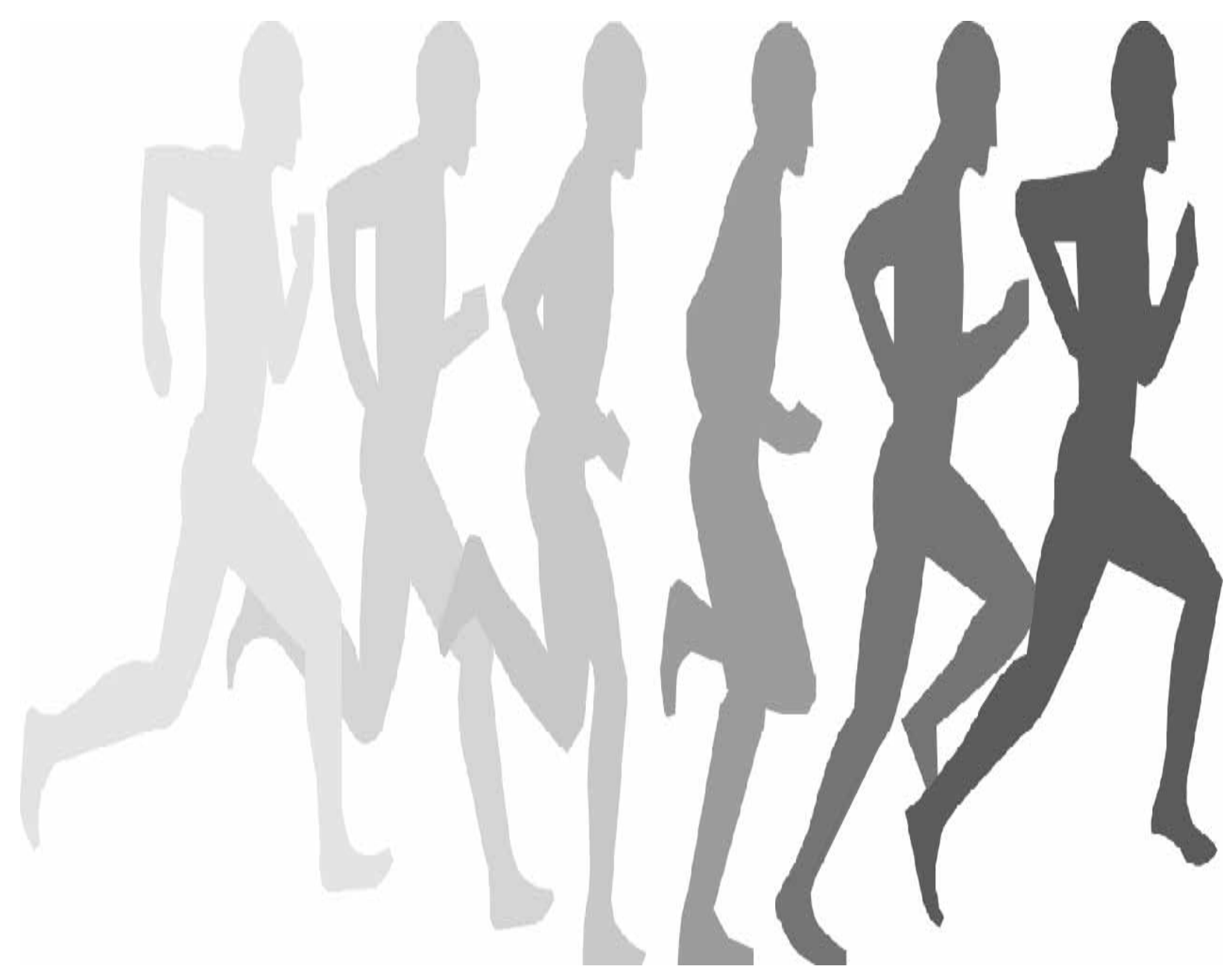

